\title{
Creativity in and between Collaborative Peer Assessment Processes in Higher Distance Education
}

\author{
Lisbeth Amhag \\ Faculty of Education and Society, Malmö University, Malmö, Sweden \\ Email: Lisbeth.Amhag@mah.se
}

Received May 28 $8^{\text {th }}$, 2013; revised June 29 $9^{\text {th }}$, 2013; accepted July $6^{\text {th }}, 2013$

\begin{abstract}
Copyright (c) 2013 Lisbeth Amhag. This is an open access article distributed under the Creative Commons Attribution License, which permits unrestricted use, distribution, and reproduction in any medium, provided the original work is properly cited.
\end{abstract}

\begin{abstract}
The study investigates in what ways the combination of self-assessment and collaborative peer assessment can support students' creative- and critical-abilities, as well as providing opportunities for meta-cognitive learning. The study is informed by sociocultural theories research traditions and computer supported collaborative learning, CSCL. Data were collected from 22 student teachers peer assessment processes, including peer feedback and self-assessment during two consecutive 15 credit web-based courses. The analytical framework was based on Toulmin's argument model (1958) and Hattie and Timperley's (2007) feedback model. The results provide a broader perspective on collaborative peer assessment processes by distinguishing, identifying and describing the meaning content in the students' peer feedback and selfassessment, and the relationships between these. Quality of content and creativity in formulating the responses can be linked to creativity as "higher order thinking skills". Peer assessment processes can thus function as creative exercises or as a tool to support such skills.
\end{abstract}

Keywords: Creativity; Distance Education; Online Learning; Peer Assessment; Peer Feedback; Self-Assessment; Self-Efficacy

\section{Introduction}

Many students today use online interactions for social purposes, but in higher education students also need to develop academic reading and writing, inquiry and problem solving to improve their learning outcomes. Academic assignments such as reports, articles and project presentations are complex types of work; accordingly, there is a need for more differentiated collaborative assessment processes, especially in distance. In this context peer assessment processes may develop students' creative- and critical-abilities, and support meta-cognitive learning. Therefore, one aim of this study is to investigate in what ways the combination of collaborative peer- and selfassessment in higher distance education can be a tool for learning in a formative or creative way (Wiliam, 2011). Another aim is to determine to which extent students aware of the cognitive aspects of their learning in their self-assessments? Can collaborative peer assessment processes be one way for students to identify strengths and weaknesses in their own and others' work? Can such processes support their creative and critical ability to reflect and assess in a appropriate ways?

The definition of combined peer- and self-assessment, according to Dochy, Segers and Sluijsmans (1999), is when the students assess peers, but they are simultaneously included as members of the group and the self must therefore also be assessed. This combination fosters creativity and knowledge (Dickhut, 2003) as "higher order thinking skills". Meta-cognitive ability is here related to a wide range of skills, such as problem solving, interpreting, communicating, reflecting and evaluating, i.e. a process of creating internal feedback (what one knows); seeking and dealing with feedback information (what one can do); evaluating their levels of understanding (what one knows about one's own cognitive ability). Assessment processes provide opportunities to practice and combine such skills in complex environments, strengthening students' confidence to work constructively, critically and creatively.

A practical benefit of implementing peer feedback, according to van der Pol, van den Berg and Admiraal (2008), is that the feedback becomes available faster during the learning process, and that more approaches are available than the teacher could ever provide alone. Topping (1998) emphases the learning benefits deriving from receiving other students' appreciations with aspects of each individual's understanding, as well being exposed to alternative strategies and solutions based on the literature. This promotes the ability to give and receive peer feedback, as well critically review different types of texts. Peer feedback can also be an intermediated step for self-assessment. Response ability is here also related to a concrete answer to a specific text in order to become a more conscious writer. A previous study (Amhag, 2011) of 30 student teachers' peer assessment contributions show that the majority of 253 peer feedback items (64\%) presented their ideas in an understandable and coherent manner, while the rest lacked convincing evidence.

Self-assessment can be a way to help students to focus their attention on the meta-cognitive aspects of their learning when they monitor the meaning content in their own assignment and the peer assessment process, and compare it with own and fellow students. Dochy, Segers and Sluijsmans (1999) describe six 
main topics of self-assessment: 1) the influence of different abilities, 2) the time effect, 3) the accuracy, 4) the effect of selfassessment, 5) methods of self-assessment, and 6) the content of self-assessment. According to De Wever, Schellens, Valcke and Van Keer (2006), and Kostons, van Gog and Paas (2010) these learning processes foster reflection on the quality of the students' assignments and the input of others. Students can use their reflections as input for self-assessment after complementing the assignment, and to support next learning assignment. Furthermore, the peer assessment processes includes creativity as "higher order thinking skills" (Meyer, 2003; Schellens \& Valcke, 2005; Wegerif, 2007; Richardson \& Ice, 2010) to develop awareness of effective contributions and discussions online, and perceive the various qualities that make the contributions relevant. It is argued here that this type of creativity is a central characteristic of academic studies.

Adams and King (1995) suggest a systematic approach with student activities such as: setting own criteria, assessment exercises, self-assessment and peer assessment. Assessment for learning, also called formative assessment by Wiliam (2011: pp. 37-39), is regarded as a process or as a tool. The process requires provision of effective feedback, active involvement of own learning, adjustment of the online teaching to take into account the result of peer assessment, influence of peer assessment on motivation and self-esteem, and the need for students to be able to assess themselves and understand how to improve. These elements, De Wever, Van Keer Schellens and Valcke (2009) contend, not only help students to make judgments about their own learning outcomes, but also allow them to consider the characteristics of competent work, and learn how to apply these criteria to their own and others' work. In a collaborative context, peer assessment enables reflections on the quality of personal contributions and the input of others, and develops awareness of creative high quality contributions to the discussions online. In these respects, peer assessment processes, conducted individually and in group, can promote students' learning and development; together with other forms of reflective interactions that support students' creative and critical ability to cooperate, reflect and assess in an effective way.

\section{Previous Research}

Increasing numbers of studies on students' collaborative learning in web-based environments have used a socio-cultural approach as their point of departure. The assumption is that considering language, communication, culture and various aspects of the social context for students' learning and development is central for our understanding of learning processes. This perspective is distinguished from other perspectives through the claim that it is not possible to understand learning solely from individual actions or development. According to Wenger (1998), the communities of practice are maintained by the participants' mutual engagement, common interests and joint enterprise, as well as a shared repertoire with a set of rules, means and working methods. Learning is not merely internal and conceptual, but is situated in time and space, and mediated through concrete activities. Participants engage in activities together and produce something that they share amongst themselves. Learning activities, can thus take the form of exchanging experiences, concepts, opinions or differing viewpoints.

Theories of Computer Supported Collaborative Learning (CSCL), with an emphasis on the importance of the social con- text for learning, are a relatively well-developed area of research within the sociocultural tradition. According to Suthers (2006), the research methodology of distance education and the CSCL enterprise covers experimental, empirical, descriptive and iterative design approaches with focus on procedural learning. While many studies have investigated students' participation in asynchronous discussion groups by an overall categorization of the content, or by examining how different technical designs of online activities can promote learning (e.g. Schrire, 2006; Strijbos, Martens, Prins, \& Jochems, 2006; Sun, Tsai, Finger, Chen, \& Yeh, 2008; Weinberger \& Fischer, 2006;), there are considerably fewer studies that analytically investigate the quality of collaborative peer assessment processes. A re- view of 15 content analysis schemes in overall categories, by De Wever, Schellens, Valcke and Van Keer (2006), shows that content analysis schemes are seldom reused or adapted, and the empirical base of the validity of the instruments is often limited. Common theoretical perspectives on the content examine cog- native presence, instructional exchanges, critical thinking, know- ledge construction, social constructivism and social networking presence.

The importance of developing self-reflective learning and critical thinking has been highlighted in several studies within the field of distance learning and education (e.g. Finegold \& Cooke, 2006; Garrison, Anderson, \& Archer, 2001; Swann, 2010; Vonderwell, 2003; Wegerif, 2006). The review byvan der Pol, van den Berg and Admiraal (2008) of online peer feedback in higher education shows significant relationship between online feedback containing concrete suggestions and a successful uptake of the feedback. Additionally, relationships can be observed between the reception of feedback and the use of this feedback by the receiver. However, Hewett (2000) demonstrates that compared to face-to-face feedback, exchanging peer feedback online may result more often in the revision of students' concrete writing tasks and use of peer ideas, whereas face-to-face peer feedback included more frequent intertextual and self-regulated idea use.

De Wever, Schellens, Valcke and Van Keer (2006) point to the significant positive impact of paying attention to ways roles of peer feedback are assigned to students. In their study, the time when these roles were introduced appeared to be important was the moment of introduction of these roles. The authors saw that it worked at the start of the discussions, but faded out towards the end. Their results indicate that peer feedback has no significant added value when dialogical exchanges are done voluntarily. It may be that teachers often take for granted that students are active spontaneously, that they realize the benefits of peer feedback, and know how to use various peer assessment processes. Other aspects have been brought to light by Saunders (1989), who investigated a combination of two factors: 1) what students do together with the tasks assigned to them as collaborators, 2) the roles and responsibilities the students assume as collaborators and the interactive structure underlying the activity. Saunders' study shows that peer assessment is often more limited than other forms of collaborative learning in the sense that it generally offers a lower degree of interactivity. He calls this process "co-responding” and argues that it affects students' possibilities for interactive meaning making, and collaborative knowledge construction.

When looking for studies on peer learning, Dochy, Segers and Sluijsmans (1999), and Topping (2005) emphasize that by assessing the work of fellow students, students also learn to 
evaluate their own work. Producing and receiving peer feedback result in considerable benefits, which justify the time, and effort that is required to engage in the learning process of peer feedback. According to Topping (2005) peer learning can include various forms of peer assessment processes and critical review before examinations, but also implies that the social aspects of learning need to be included in the quality of education. This view is also supported by Shekary and Tahririan (2006), who state that peer assessment in language-related episodes (LRE) resembles any other form of collaborative learning. Their study suggests that students benefitted most from the nature of acceptance, rather than from its mere presence. Other studies (e.g. Dysthe, 2002; Amhag \& Jakobsson, 2009; Amhag, 2010, 2011, 2012) illustrate the potential of online peer feedback as the range of meaning-mediating possibilities, which are providing throughout the process. Peer feedback can thus ideally function as an active tool that allows students to present with self-reflective and interdependent arguments and thoughts, where each student can contribute with his or her own expertise and receive new information and experiences from others. In order to shed more light on collaborative peer assessment processes in higher distance education, the present study addresses the following research questions:

- In what way do the students identify the meaning content in their own and others' peer feedback?

- In what way do the peer assessment processes support students' creative- and critical abilities to reflect and assess in a formative way?

\section{Method}

Data were collected from 22 student teachers' (women $=15$, men $=7$ ) peer assessment processes during twenty weeks of participation in the first two consecutive 15 credit web-based modules in the distance teacher training program, Teacher Education, 90 credits. One assignment in each module was executed in an online learning management system (LMS), where students can share their course assignments, give and receive peer feedback and evaluate their peer assessment process in a self-assessment, both directly and retrospectively. In both modules the students were divided into the same six groups, with five to seven individuals in each. Each group included both men and women. At the start of the first course the students had worked with assessment exercises showing how to provide peer feedback in their groups. The exercise which were used as a base in this study are grounded on criteria supported by Dysthe and colleagues (2011) that specify: as they read each other's assignments they should start with capturing text focus or purpose, then indicate interesting or unclear summary and finally formulate briefly in their own words what they consider most important, ask questions or provide explanations and clarifications or suggest alternative solutions and/or advice and discuss problems on the basis of literature and theories. The students are not asked to grade the meaning content in the course assignments.

\section{Implementation}

The present study focuses on the second course assignment in module 1 , where the students worked both individually and in groups with different cases of teacher leadership. One concerned an official case about a pupil who was exposed for humiliating treatment at school, while the other was the students own case - a story that illustrates a situation in which pupils, parents and/or teachers, felt that they had been badly treated. In module 2, the students worked both individually and in groups with their own cases of bilingualism and second language learning. They had individually observed teaching situations in school, and in the assignment they were requested to describe and analyse one of situations they had observed, explaining the circumstances and providing their own didactic suggestions on how to manage this situation.

In both modules the same rules and procedure were followed with respect to the combination of collaborative peer- and selfassessment were used. In the first step, the students were asked to submit their own particular contribution to the course assignment in their groups' discussion forum by a specified deadline, where they could either download or read their fellow students assignments online. In the second step, the students were requested to think critically about the content of the contributions, as specified in the course syllabus, and write a brief comment in which they express their own perspective on the arguments presented in the initial contributions. These comments were submitted to their groups' discussion forum, also by a specified deadline. In the third step, in module 1 the students were asked to self-assess the quality of both their own peer feedback and additionally analyse the comments on the didactic suggestions and summarize their own learning in the course of these processes. The final compilations of assessments and analyses were submitted in the LMS for assessment by the teachers.

\section{Analysis of the Combination of Peer- and Self-Assessment}

The analysis was conducted in two phase (Patton, 2002). The first phase involved identifying the and describing the content of the 22 students' collaborative peer feedback, a total of 155 items, using Toulmin's (1958) argument pattern (TAP). TAP is based on practical relationships or approaches that refer to cognitive knowledge processes, such as thinking, problem solving, concept formation, perception, attention, memory and reflection. Toulmin points out that the argument model is a simplification of the complexity and diversity of an argument. Nevertheless, carefully considering the various suggestions and solutions in the contributions, is a part of the learning process, and is important to handle the logical relationship between them in writing. Toulmin describes how writers and readers can deal with texts, and how they can use the resources of texts to determine what they mean-or rather, some possible meanings. The description of these fundamental elements of meaning is achieved with an argument model containing six elements/objects (1958: pp. 98, 101, 103). Three elements are mandatory, while the remaining three are optional, since they are frequently found in texts, but not always. The basic argument model thus consists of three mandatory elements: C (claim), D (data) and W (warrant). The extended argument model includes the optional elements; Q (qualifier), R (rebuttal) and B (backing). The task is to show students how to present their ideas in an understandable and coherent manner, based on these data and the claims of the original opinion, and employing the optional elements to some extent.

The first mandatory element/object, claim (C), is a superior standpoint with a relationship to any determination or assertion 
about what exists, or the justification of the norms or values that people hold, or desire for acceptance of the claim. The second mandatory element/object, data (D), is the information which the claim is based on, and may consist of previous research, personal experience, common sense, or statements used as evidence to support the claim. The third mandatory element/ object, warrant (W), is explicit or implicit argument that explains the relationship between data and claim, for example, with words such as because or since. The first optional element/ object, qualifier $(\mathrm{Q})$, is related to the claim and indicates the degree of strength in the claim of using peculiar comments, for example, with words such as thus or so. The second optional element/object, rebuttal (R), is connected to the qualifier (Q), providing statements or facts that either contradict the claim, data or rebuttal, or qualify an argument, with words such as but and unless. The third optional element/object, backing (B), can be connected directly to the warrant (W), with often implicit motives underlying claims, expressed with words such as because of or on account of. According to Toulmin (1958), all terms of the basic argument model (C, D \& W) are required to describe, or analyze the argument. A revised and developed version of TAP based on Toulmin (1958); Kneupper (1978); Simon, Erduran \& Osborne (2006) is given in Figure 1.

The second phase of analysis involved discovering and identifying in what ways the students' focus on the meta-cognitive aspects of their learning increased in the process of examining the meaning content in their own and others peer feedback, and comparing them in their self-assessments. This phase of the analysis employed Hattie and Timperley's (2007: pp. 86-87) three effective feedback questions: Where am I going? (What are the goals?); How am I going? (What progress is being made toward the goal?); and Where to next? (What activities need to be undertaken to make better progress?). These three questions correspond to the design of feed up, feed back and feed forward. How successfully the students answer these questions are, according to Hattie and Timperley, partly dependent on the level at which the feedback operates, to reduce the gap across the four levels of: addressing the task itself; the main process; the self-regulated actions; and the self as a person, i.e. where the students are, and where they are aiming to be. Hattie and Timperley argue that these four levels are linked to the power of feedback. To be successful is in this model defined as; tackling more challenging tasks, or appreciating "higher order thinking skills"; error detection skills; better strategies to complete the task or obtain more information. A revised version of Hattie and Timperleys model of effective feedback to enhance learning is given in Figure 2.

The model of Hattie and Timperley (2007), show in Figure 2 works to reduce the gap between achievement and aims across the four levels of feedback: the task (FT); the processing (FP); the self-regulation (FR); and the self-level (FS).

Feedback about the task (FT) is how well the process is linked to the course assignment, helping the task to be understood or performed. This feedback might concern acquiring more or different information and/or use of knowledge with statements and reproductions of information from others, such as authors, teachers and fellow students. According to Hattie and Timperley (2007), this is the most common type of feedback. It is sometimes called for "corrective feedback" or "knowledge of results", and can relate to correctness, broader

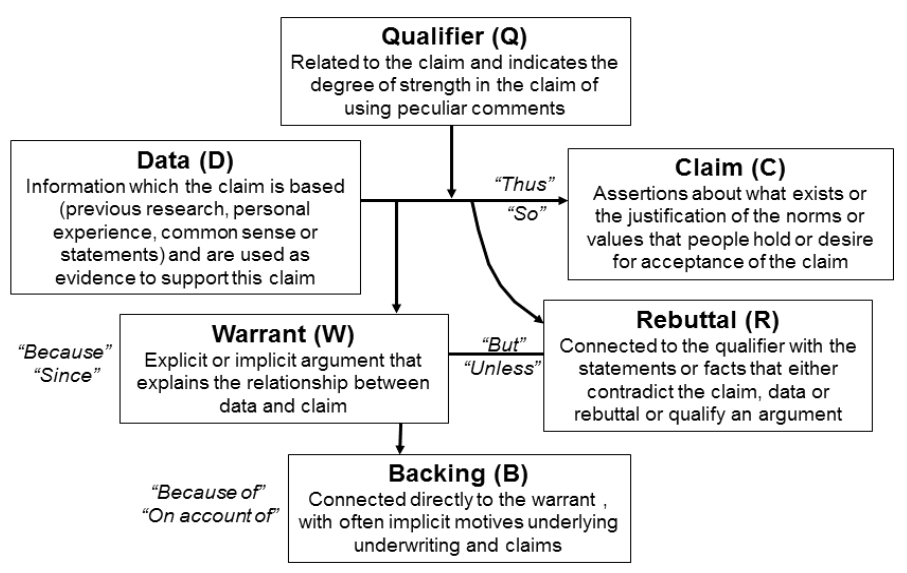

Figure 1.

Revised version of Toulmin's argument pattern.

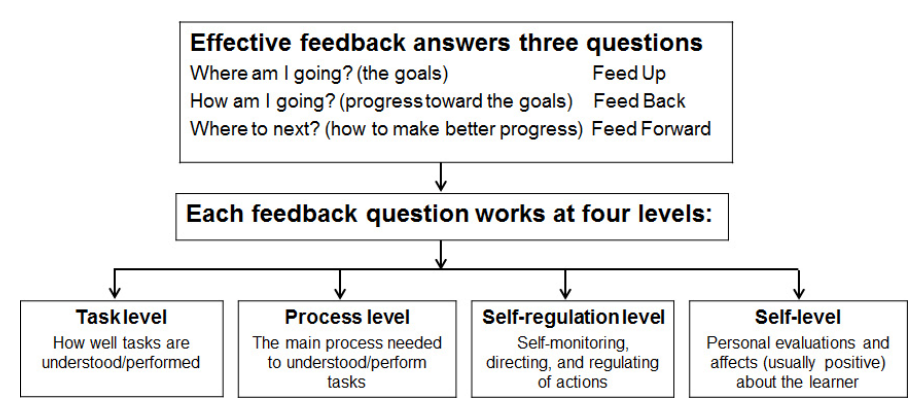

Figure 2.

Revised version of Hattie and Timperleys model (2007: p. 87). 
literature and formalities, or some other criterion related to task accomplishment. One of the problems at FT-level is that the meaning content is often not linked to other tasks or to the use of own words or reflections.

Feedback about the process level (FP) is more specific to the processes underlying tasks or relating and extending tasks. Such feedback shows a clear purpose with underlying motives and relations that broadens the meaning content. In the present study this might concern relationships between data and claims in teacher leadership, or with respect to bilingualism and second language learning, how these relations are perceived by the student, and also the student's perceptions, or discussions about different suggestions of alternative solutions, or didactic proposals on the basis of course literature.

Feedback about the self-regulation level (FR) involves selfmonitoring, directing and regulation of actions, such as interplay between engagement and meta-cognitive aspects in the students' self-assessment, control of and self-confidence regarding these processes, and to progress toward the goals. Such self-regulation creates internal feedback, feelings of self-efficacy, thoughts and reflections and actions that are planned and adapted to the attainment of personal goals. This in turn can lead to seeking and dealing with feedback information, evaluating the levels of understanding, or developing strategies and proficiency at seeking help.

Feedback about the self-level (FS) rarely contributes to more engagement, improving personal evaluation, and self-efficacy, increasing participation towards the learning goals, or understanding of the task. The effects at the self-level are too weak, or unhelpful about ways of performing the task, and too prejudiced by students' self-concept to be effective. It is here important to distinguish between praise addressed to the person or linked to the task. Personal praise may be perceived and interpreted in different ways, and therefore has low impact on learning and development, in contrast to the praise that is directed towards the work, self-regulation, engagement, or processes related to the task, its performance and the students critical ability (Hattie \& Timperley, 2007: p. 96).

\section{Results}

The study led to two main sets of results. The first results, summarized in Table 1 below, give a picture of the 22 students' collaborative peer feedback items ( $\mathrm{N}=155,89$ in module 1 and 66 in module 2). They show to which extent the meaning content of these feedback items contained Toulmin's (1958) mandatory elements; claim, data and warrant, which are related more and less to the optional elements; backing, qualifier and rebuttal. The results in Table $\mathbf{1}$ indicate that the students principally presented their ideas in an understandable and coherent manner in both modules, based on these data, claims and warrants of the original opinions. Two-thirds of the contributions (63\%) contained all three of Toulmin's mandatory elements/objects (C, D, W), with assertions about the cases of teacher leadership in module 1 , and bilingualism and second language learning in course 2 with justification of the norms, values and solutions, confirmations from own experiences and/or literature, and the relationship between them; combined with one or two of the optional elements $(\mathrm{Q}, \mathrm{R}, \mathrm{B})$ with proposals, statements, or facts that either contradict the claim, data, or rebuttal, or qualifying the argument by underlying motives. $36 \%$ contained three of the mandatory or optional elements/
Table 1.

Level of elements in the students' collaborative peer feedback items.

\begin{tabular}{cccc}
\hline Level of elements & Course 1 & Course 2 & Total \\
\hline $\begin{array}{c}\text { CD, CW, CR, DR, WB } \\
\text { CDW, CDR, CDQ, } \\
\text { CWR, DWB }\end{array}$ & $1(1 \%)$ & 0 & $1(1 \%)$ \\
CDWB, CDWQ, & $55(62 \%)$ & $43(65 \%)$ & $98(63 \%)$ \\
CDWR, CDWRB & $23(35 \%)$ & $56(36 \%)$ \\
Total & $89(100 \%)$ & $66(100 \%)$ & $155(100 \%)$
\end{tabular}

Note: C, claim; D, data; W, warrant; B, backing; Q, qualifier; R, rebuttal.

objects, and only $1 \%$ contained two of these elements. There is no significant progression between the two modules.

The second set of results, based on the 22 students' 44 selfassessments (one in each module) are illustrated in four excerpts. These give a broader picture of the collaborative peer assessment processes and show to what extent the students' focus on the meta-cognitive aspects of their learning may have improves when they monitor the meaning content in their own and others peer feedback, and compare the content in their self-assessments. In module 1, it appears that many students repeated in their self-assessment what they had written before in their collaborative peer feedback. This kind of meaning content was categorized as feedback on the task level (FT), because the students showed knowledge of results. Nevertheless, broader literature and formalities, or some other criterion related to task accomplishment, would have been required as evaluations and reflections of own learning. In both modules a third of the 44 self-assessments (17 pcs.) contained feedback on the task level (FT), but nearly twice as many in module 1 (11 pcs.), as in module 2 (6 pcs.). The first example, in Figure 3, gives a picture of the task level (FT). The excerpt is taken from module 1 , where the students worked both individually and collaboratively with cases of teacher leadership. A student (here named Laura), gets peer feedback from fellow student Sarah on her case.

Within this contribution is it possible to describe and identify the meaning content on the task level (FT), because Sarah's meaning content is linked to the course assignment and performed in an adequate manner. Sarah starts with a statement that teachers must "be careful with the position of power they have over the pupils", which also is the claim in this excerpt. The data are a part of the claim, which is supported in the literature about the pupil's intrinsic value and teachers' treatment of pupils. The warrant is here explicit; because "they [classmates] promised to be a witness to the situation which the boy was accused of", and explains the relationship between the data in Education Law, and the Sarah's claim about teachers' power over pupils. Sarah's statement: "I am aware that there is a great responsibility", is an implicit backing in this case, because of the following meaning: What I write is highlighted in the literature and therefore, I write it in my post. But the utterance does not present Sarah's own understanding. If we look at the qualifier of the claim in this excerpt, so there is a connection concerning unfair treatment of the boy and abusive treatment. Finally, the peer feedback contains a rebuttal, which could start with a word like but "the boy has his classmates around him", and that the "more-against-one" situation made it difficult for the boy to be himself and was violating him even more. Sarah 
thus used knowledge with statements and reproductions from other authors and fellow students. However, there is a need for broader use of literature, and evaluations and reflections on her own learning. A summary description of the task level (FT) in the peer assessment processes in Excerpt $\mathbf{1}$ is given in Figure 3.

The second example is taken from module 2, where the students worked both individually and collaboratively with cases of bilingualism and second language learning. In both modules nearly a third (14 pcs.) of the 44 self-assessments contained feedback on the process level (FP), but more than three times as many assessments in module 2 (11 pcs.) contained this type of feedback, compared to module 1 (3 pcs.). In Excerpt 2, the same student Sarah, summarizes the peer assessment process connected to her own and fellow students' didactic suggestions about her case.

In this excerpt, it is possible to describe and identify the meaning content on the process level (FP), because Sarah captures the text focus between the data from course literature, and the claims that pupils could take part of literature in their native language to gain a deeper understanding how people have lived and thought in different cultures, and at different times. She also discusses further, on the basis of the course literature, her beliefs that teachers can create various opportunities for the pupils to write, and suggests alternative solutions of teaching design, as well extending the meaning content about the difficulty for the pupils to focus on both languages.

If we look at the specific elements in this excerpt, the claim consist of Sarah's statement with didactic suggestions that the pupils with Swedish as a second language would be able to read Swedish literature in their native language. The data is from the literature of Lindberg $(2005,2011)$ and the publication of Swedish National Agency for Education (Skolverket, 2003) publication about Swedish as a second language. The warrant

\begin{tabular}{|c|c|}
\hline Level of peer assessment & \\
\hline $\begin{array}{l}\text { FT, feedback on the } \\
\text { task level }\end{array}$ & $\begin{array}{l}\text { - } \quad \text { how well a task is understood or performed } \\
\text { - } \quad \text { corrective feedback or use of knowledge } \\
\text { - } \quad \text { statements and reproductions from others } \\
\text { - lack of own reflections on learning }\end{array}$ \\
\hline
\end{tabular}

Figure 3.

Summary description of the task level.

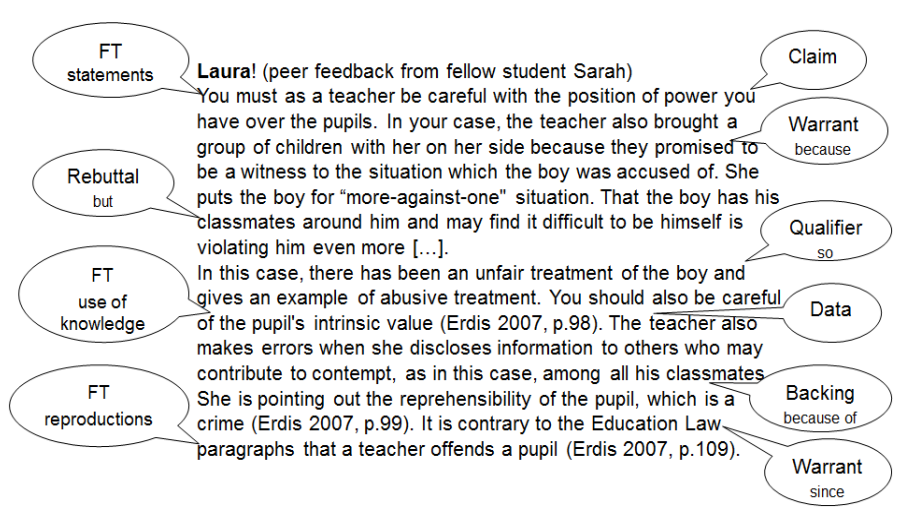

Excerpt 1.

Task level of peer assessment and specific elements in the peer feedback.

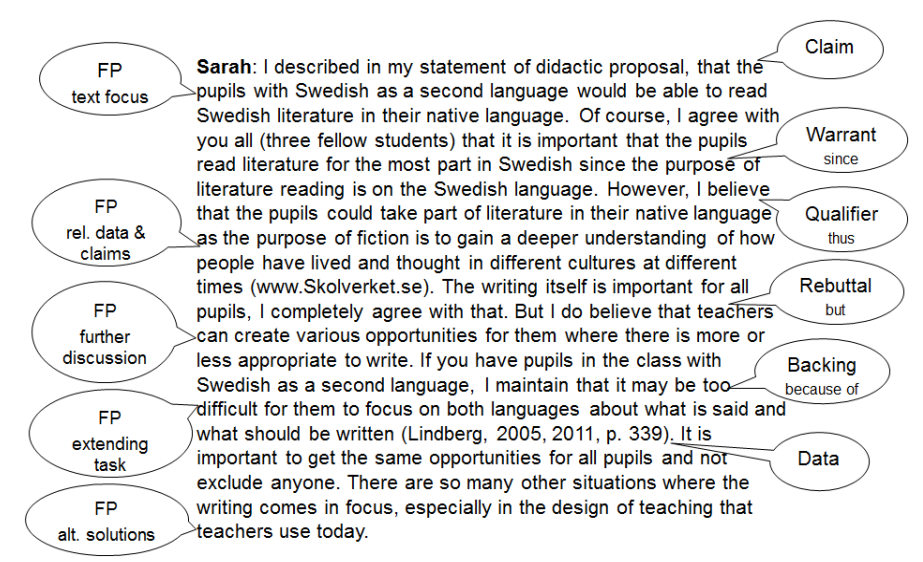

Excerpts 2.

Process level of peer assessment and specific elements in the self-assessment. 
is here explicit "since the purpose of literature reading is in Swedish language”. Sarah's maintains "that it may be too difficult for them [the pupils] to focus on both languages", which constitutes the backing in this argument because of the difficulties. If we review the qualifier of the claim, there is a connection; presenting Sarah's beliefes thus she considers that the pupils would be able to read Swedish literature in their native language. Lastly, the self-assessment also contains a rebuttal, which starts with "But I do believe that teachers..." to qualify her argument. In summary, Sarah's contribution is linked in specific ways to the processes underlying the motives with a clear purpose and relations between data and claims that broaden the meaning content. A summary description of the process level (FP) in the peer assessment processes in Excerpt $\mathbf{2}$ is given in Figure 4.

The third example is taken from module 1, where the students worked both individually and collaboratively with cases of teacher leadership. Nearly a quarter of the 44 self-assessments (10 pcs.) contained feedback on the self-regulation level (FR), but where twice as many are found in module 1 (7 pcs.) as in module 2 (3 pcs.). In the third excerpt, Hannah summarizes the online peer processes from her own peer feedback to five fellow students' cases.

In the excerpt it is possible to describe and identify the meaning content on the self-regulation level (FR), because Hannah reflects that their group have covered a fairly wide range of different leadership problems. She has looked for and dealt with feedback information to bring in the other students' opinions, although she realises that they do not have an identical picture of how the school will conduct its leadership. Her self-efficacy feeling, e.g. the belief in her own ability to perform course activities successfully about leadership ability, is to be more active in source references, but she shows proficiency at seeking help on the issue of how teachers can bring all students together. Hannah also evaluates her own understanding and alternative strategies for how to work systematically with prolonged equal plans, and how to generate empathic students.

If we look at the specific elements in this excerpt, the claim consist of Hannah's statement that their group have covered a fairly wide range of different leadership problems, though far from all which is the rebuttal in the argument. The data is from the literature on children and pupil safety legislation, and the warrant explains the relation between Hannah's question why schools don't open their eyes about their prolonged equal plans, as well as in relation to the explicit backing of the warrant because of the absence of systematic work. Finally, she qualifies her performance of the course assignments by resolving to be more active in source references. In summary, Hannah expresses internal feedback through her thoughts and reflections about different leadership, the schools equality plans and discrimination legislation. She evaluates her literature reading and source references and is seeking for what is wrong in the schools systematic work to generate empathic students. A summary description of the self-regulation level (FR) in the peer assessment processes in Excerpt $\mathbf{3}$ is given in Figure $\mathbf{5}$.

The fourth example is taken from module 1, by Eric's comment about his online peer feedback to fellow students' cases of teacher leadership and module 2, with Maria's comment about her online peer feedback, compared to fellow students' cases of bilingualism and second language learning with didactic suggestions. In both modules, only three students' assessments (one in module 1 and two in module 2) contained feedback on the self-level (FS).

Within these two excerpts in Excerpt 4, it is possible to describe and identify the meaning content on the self-level (FS), because Eric is only claiming that common to the described cases on violations in his group has been that there are no concrete action plans for how the measures are to be deployed and when. He qualifies the argument of teacher leadership with a rebuttal that more prevention efforts are also missing, but without any concrete suggestions of his own or taken from course literature for how pupils shall behave towards each other. The comments contain little task-related information, or visible improvement of his own personal evaluations and critical ability, or achievement of learning goals.

If we look at Maria's contribution, she claims that the group's didactic, alternative suggestions on bilingualism and second language learning are consistent with her own didactic

\begin{tabular}{|c|c|}
\hline Level of peer assessment & \\
\hline $\begin{array}{l}\text { FP, feedback on the } \\
\text { process level }\end{array}$ & $\begin{array}{l}\text { - } \text { capturing the text focus or purpose } \\
\text { - } \text { extending tasks } \\
\text { - perceptions and relations of data and claims } \\
\text { - } \text { suggestions of alternative solutions } \\
\text { - discussing problems on the basis of literature }\end{array}$ \\
\hline
\end{tabular}

Figure 4.

Summary description of the process level.

\begin{tabular}{|c|l|}
\hline Level of peer assessment & \\
\hline & $\begin{array}{l}\text { - creating internal feedback, thoughts and reflections } \\
\text { - feelings of self-efficacy }\end{array}$ \\
$\begin{array}{c}\text { FR, feedback on the } \\
\text { self-regulation level }\end{array}$ & $\begin{array}{l}\text { - seeking and dealing with peer feedback information } \\
\text { - evaluating their levels of understanding and } \\
\text { strategies }\end{array}$ \\
& - proficiency at seeking help
\end{tabular}

Figure 5.

Summary description of the self-regulation level. 
suggestions concerning a pupil. She only qualifies the argument with her feelings; therefore, she has no more to add in this section. It appears that Marias commitment is lacking, which does not lead to an improvement of her critical ability, or support achievement of learning goals. In summary, Eric and Maria's contributions do not display increased engagement in their selfassessment or their understanding and progress in their understanding of and participation in the learning goals and peer assessment processes. A summary description of the self-level (FS) in the peer assessment processes in Excerpt $\mathbf{4}$ is given in Figure 6.

Throughout the two-phase analysis, it has appeared that it is possible to describe the development of the collaborative peer assessment processes, not only as an individual appropriation, but also as an extended, collective competence to collaborate within the group. In this way, the excerpts only constitute descriptions of the four levels in the collaborative peer assessment processes (cf Hattie \& Timperley, 2007) to the extent that the students combine peer feedback and self-assessment as a tool for learning in a formative or creative way (Dickhut, 2003; Wiliam, 2011). This does not mean that these particular students' contributions displayed all the aspects of these feedback levels a group of other students might have produced in this situation. A summary of the four levels in the peer assessment processes in this study is provided in Figure 7.

\section{Research Contributions and Implications}

Previous research on collaborative web-based learning processes has focused on various aspects summarized by De Weaver, Schellens, Valcke and Van Keer (2006). The results of the present study provide a broader and complementing perspective on collaborative peer assessment processes by distinguishing, identifying and describing the meaning content in the students' peer feedback and self-assessment, as well as the relationships observed within and between their contributions.

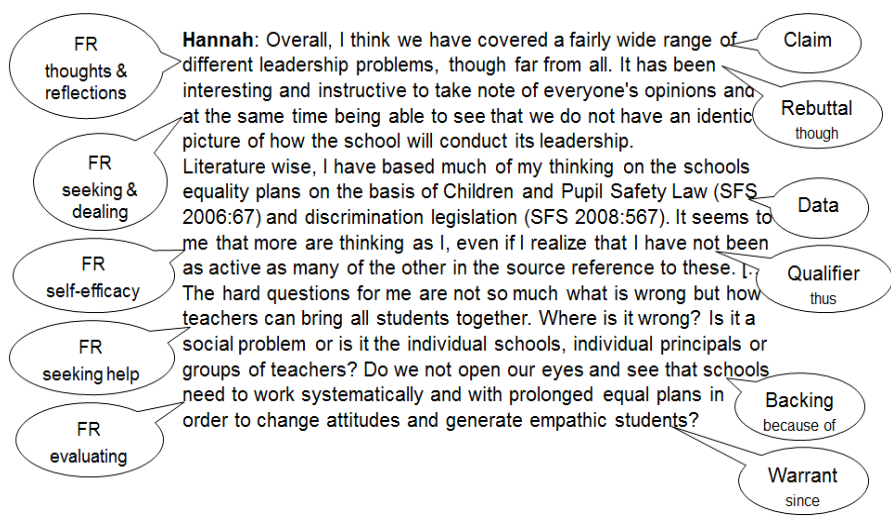

Excerpt 3.

Self-regulation level of peer assessment and specific elements in the self-assessment.

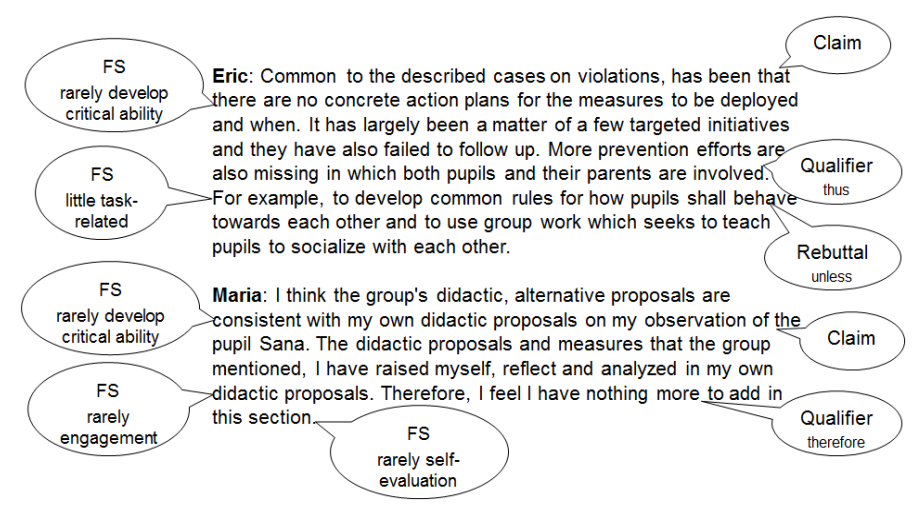

Excerpt 4.

Self-level of peer assessment and specific elements in the self-assessment.

\begin{tabular}{|c|c|}
\hline Level of peer assessment & \\
\hline $\begin{array}{l}\text { FS, feedback on } \\
\text { self as a person }\end{array}$ & $\begin{array}{l}\text { - } \text { contains little task-related information } \\
\text { - rarely converted into more engagement in learning } \\
\text { - rarely improving self-evaluations } \\
\text { - rarely developing critical ability }\end{array}$ \\
\hline
\end{tabular}

Figure 6.

Summary description of the self-level. 


\begin{tabular}{|c|l|}
\hline $\begin{array}{c}\text { Level of peer } \\
\text { assessment }\end{array}$ & \\
\hline $\begin{array}{c}\text { FT, feedback on } \\
\text { the task level }\end{array}$ & $\begin{array}{l}\text { - how well a task is understood or performed } \\
\text { - corrective feedback or use of knowledge }\end{array}$ \\
\hline - statements and reproductions from other
\end{tabular}

Figure 7.

Summary of the four levels in the peer assessments.

The results indicate a potential for deeper learning in and between collaborative peer assessment processes, including creativity as "higher order thinking skills" (Shaheen, 2010), both in terms of the peer process or as use of tools, such as peer feedback and self-assessment to solve problems (Dickhut, 2006).

Contributions at the four levels of feedback in the collaborative peer assessment processes profressed between module 1 and module 2. This point of departure is based on Hattie and Timperley's (2007) three feedback questions; Where am I going? (What are the goals?); How am I going? (What progress is being made toward the goal?); and Where to next? (What activities need to be undertaken to make better progress?), which correspond to the design of feed up, feed back and feed forward. The three questions are partly dependent on the level at which the feedback operates; the task level (FT) about how well the goals of the two assignments were understood; the process level (FP) about the main processing needed to be understood in the two assignments, where the students worked both individually and collaboratively with cases of teacher leadership in module 1 , and cases of bilingualism and second language learning in module 2; the self-regulation level (FR) about self-monitoring, directing and relating their assignments and the peer assessment process; and the self-level (FS) about the students' personal evaluation and emotions concerning their learning, i.e. where the students are and where they are aiming to be.

Overall, in both courses, nearly a third (14 pcs.) of the 44 self-assessments contained feedback on the process level (FP), with more than three times as many in module 2 (11 pcs.) as in module 1 ( 3 pcs.), especially the connection to students text focus or purpose, and relations between own didactic suggestions, and course literature with suggestions of alternative solutions. Likewise the self-assessments on the task level (FT) dropped from nearly twice as many in module 1 (11 pcs.) as in module 2 (6 pcs.), evolving to more linking to other tasks and use of own words or reflections. For example, Sarah's contribution develops between module 1 and module 2, from using reproductions of other authors' texts to broadening the meaning content in her own words and using others student's arguments and justifications. Few students display self-regulated ability already in module 1, like Hannah, when she uses her own thoughts and reflections on various actions and strategies. However, it appears that most students were unfamiliar with practice of giving/receiving and integrating peer feedback and above all, self-assessing their own learning. This result indicates that peer feedback and self-assessment must be trained and integrated continuously in teaching with different methods and criteria (Adams \& King, 1995) to foster creativity and knowledge as "higher order thinking skills, which can be seen at the processes behind creativity (Dickhut, 2003).

The material clearly shows that the valuable effects in and between the collaborative peer assessment processes with peer feedback and self-assessment reside above all in two aspects of the activities; an increasing ability to provide and take in others' peer feedback, as well as an increasing ability to evaluate their levels of understanding in their self-assessments. The value of what the students' write and how creative they are when formulating the responses, is here measured by to which extent they use their own words in ways that broaden and expand other students and writers perceptions. The students can identify strengths and weaknesses in their work, which also promotes their critical ability to reflect, assess, evaluate, plan and take responsibility for their own learning (van der Pol, van den Berg \& Admiraal 2008). Therefore, is it possible to claim that the impact in and between collaborative peer assessment processes is connected to the power of feedback, and the intermediate step of qualitative self-assessment can be seen as "wise thinking” and to some extent "creative thinking” (Craft, 2006).

The second set of evidence suggest that the quality of the meaning content in the students' self-assessments $(\mathrm{N}=44)$ also evolved between the two modules. The majority of the students (82\%) self-assessed others' peer feedback containing didactic suggestions, and compared them with their own suggestions in 
module 2, compared to module 1, only half of the students merely repeated what they had written before in their peer feedback in their self-assessment. A lack of personal thoughts and reflections could also be observed. These qualitative differences could be distinguished, identified and described by combining Toulmin's (1958) argument model which shows the complexity and diversity in an argument, and Hattie and Timperley's (2007) four levels of feedback that shows the complexity and diversity in and between the different levels. The analysis was summarized and described in four clarifying excerpts. Self-assessment is a self-regulatory proficiency, which is powerful in selecting and interpreting content of knowledge in ways that provide feedback. The author's own experiences from teaching in higher education on distance courses and comments by students', shows that they learn more by giving peer feedback, than by receiving peer feedback. When they give peer feedback they must deal with texts, and learn how they can use the resources of texts to determine what they mean — or rather, identify some possible meanings. They future learn how the meaning content can be formulated briefly in their own words to express what they consider most important, ask questions, provide explanations and clarifications, or suggest alternative solutions and/or advice and discuss problems on the basis of literature and theories. The dimension of students' appreciations with aspects of aspects of other students' understanding of an issue; as well searching for alternative strategies and solutions based on literature have the potential to expand their creative and critical abilities to give and receive peer feedback (Topping, 1998; Dochy, Segers, \& Sluijsmans 1999). It can therefore be argued, that the added value of collaborative peer assessment process can be encouraged through various creative exercises (Dickhut, 2003).

The third set of evidence obtained in this study, indicates that it is not enough to give and receive peer feedback in order to develop the students' self-regulating ability to self-assess their own learning in a qualitative manner. Nearly a quarter of the 44 self-assessments (10 pcs.) contained feedback on the selfregulation level (FR), notable twice as many in module 1 (7 pcs.) as in module 2 (3 pcs.). Perhaps the students were unsure of how they would self-assess their own peer feedback in module 2 with didactic suggestions relating to bilingualism and second language learning, compared to how they felt about selfassessing a discussion of various cases of teacher leadership. All students have experiences from their own school practice and different teachers' leadership, but not all the students had personal experience about how to teach with respect to bilingualism and second language learning. This uncertainty may have had effects on students ability to evaluate their levels of understanding and strategies and/or feelings of self-efficacy, i.e. the belief in their own ability to perform course activities successfully (Hattie \& Timperley, 2007). The results thus indicate that there is a clearly also a need for methods and activities to teach self-assessment in higher education, in order to better develop self-regulated aspects and meta-cognitive abilities. Important learning aims include the ability to consider the characteristics of competent work, and knowing how to apply these criteria on their own work (Dochy, Segers, \& Sluijsmans, 1999).

When students have the meta-cognitive skills of self-assessment, they are able to evaluate their own levels of understanding, their efforts and strategies used on course assignments, others' peer feedback and alternative solutions, as well as their progress in relation to their learning goals and expectations.
They are also able to assess their own learning outcome relative to others' perceptions and relations of data, claims and warrants in course literature and own experiences. As students become more experienced in self-assessment, multiple dimensions of learning outcome can be assessed. Nevertheless, most important is that teachers and students offer insights into "why" and "where" they shall give and receive peer feedback-as well as extending their understanding of "how" creativity is important for self-assessment.

An important implication is related to future research within the field of online learning, and how we might implement and understand what is happening in and between collaborative peer assessment processes. It can be concluded that a larger investment in supporting the students should be made from the start of the course, by exposing them frequently to peer feedback and self-assessment experiences; by implementing peer feedback and self-assessment training (De Wever, Van Keer Schellens, \& Valcke, 2009).

\section{REFERENCES}

Adams, C., \& King, K. (1995). Towards a framework for student selfassessment. Innovations in Education \& Training International, 32, 336-343. doi:10.1080/1355800950320405

Amhag, L. (2012). High school students' argument patterns in online peer feedback. In E. F. P. M. Pumilia-Gnarini, E. Pacetti, J. Bishop, \& L. Guerra (Eds.), Handbook of research on didactic strategies and technologies for education: Incorporating advancements, 2, 711-723. http://www.igi-global.com/chapter/high-school-students-argument-p atterns/72113

Amhag, L. (2011). Students' argument patterns in asynchronous dialogues for learning. In Research highlights in technology and teacher education (pp. 137-144) Ed/ITLib Digital Library. http://storefront.acculink.com/aace

Amhag, L. (2010). Between I and other. Web-based student dialogues with arguments and responses for learning. $\mathrm{PhD}$ Thesis, Malmö: Malmö University, Malmö Studies in Educational Sciences.

Amhag, L., \& Jakobsson, A. (2009). Collaborative learning as a collective competence when students use the potential of meaning in asynchronous dialogues. Computers \& Education, 52, 656-667. doi:10.1016/j.compedu.2008.11.012

De Wever, B., Schellens, T., Valcke, M., \& Van Keer, H. (2006). Content analysis schemes to analyze transcripts of online asynchronous discussion groups: A review. Computers \& Education, 46, 6-28. doi:10.1016/j.compedu.2005.04.005

De Wever, B., Van Keer, H., Schellens, T., \& Valcke, M. (2009). Structuring asynchronous discussion groups: The impact of role assignment and self-assessment on students' levels of knowledge construction through social negotiation. Journal of Computer Assisted Learning, 25, 177-188. doi:10.1111/j.1365-2729.2008.00292.x

Dickhut, J. E. (2003). A brief review of creativity. www.personalityresearch.org/papers/dickhut.html

Dochy, F., Segers, M., \& Sluijsmans, D. (1999). The use of self-, peerand co-assessment in higher education: A review. Studies in Higher Education, 24, 331-350. doi:10.1080/03075079912331379935

Dysthe, O. (2002). The learning potential of a web-mediated discussion in a university course. Studies in Higher Education, 27. doi:10.1080/03075070220000716

Dysthe, O., Hertzberg, F., \& Løkensgard Hoel, T. (2011). Writing to learn: Writing in Higher Education (2nd ed.). Lund: Studentlitteratur.

Erdis, M. (2007). Law for educators. Lund: Studentlitteratur.

Finegold, A. R. D., \& Cooke, L. (2006). Exploring the attitudes, experiences and dynamics of interaction in online groups. The Internet and Higher Education, 9, 201-215. doi:10.1016/j.iheduc.2006.06.003

Garrison, D. R., Anderson, T., \& Archer, W. (2001). Critical thinking, cognitive presence and computer conferencing in distance education. The American Journal of Distance Education, 15, 7-23. 
doi:10.1080/08923640109527071

Hattie, J., \& Timperley, H. (2007). The power of feedback. Review of Educational Research, 77, 81-112. doi:10.3102/003465430298487

Hewett, B. L. (2000). Characteristics of interactive oral and computermediated peer group talk and its influence on revision. Computers and Compisition, 17, 265-288. doi:10.1016/S8755-4615(00)00035-9

Kneupper, C. W. (1978). Teaching argument: An introduction to the Toulmin model. College Composition and Communication, 29, 237241. doi: $10.2307 / 356935$

Kostons, D., van Gog, T., \& Paas, F. (2010). Self-assessment and task selection in learner-controlled instruction: Differences between effective and ineffective learners. Computers \& Education, 54, 932940. doi:10.1016/j.compedu.2009.09.025

Lindberg, I. (2011). About school's multi-lingual capital (2nd ed.). Stockholm: Liber,

Meyer, K. (2003). Face-to-face versus threaded discussions: The role of time and higher-order thinking. Journal of Asynchronous Learning Networks, 7, 55-65.

Patton, M. Q. (2002). Qualitative research \& evaluation methods. London: Sage Publications.

Richardson, J. C., \& Ice, P. (2010). Investigating students' level of critical thinking across instructional strategies in online discussions. Internet and Higher Education, 13, 52-59. doi:10.1016/j.iheduc.2009.10.009

Saunders, W. (1989). Collaborative writing tasks and peer interaction. International Journal of Educational Research, 13, 101-112. doi:10.1016/0883-0355(89)90019-0

Schellens, T., \& Valcke, M. (2005). Collaborative learning in asynchronous discussion groups: What about the impact on cognitive processing? Computers in Human Behavior, 21, 957-975. doi:10.1016/j.chb.2004.02.025

Schrire, S. (2006). Knowledge building in asynchronous discussion groups: Going beyond quantitative analysis. Computers \& Education, 46, 49-70. doi:10.1016/j.compedu.2005.04.006

Shaheen, R. (2010). Creativity and Education. Creative Education, 1, 166-169. doi:10.4236/ce.2010.13026

Simon, S., Erduran, S., \& Osborne, J. (2006). Learning to teach argumentation: Research and development in the science classroom. International Journal of Science Education, 28, 235-260. doi:10.1080/09500690500336957
Skolverket (2003). Swedish as a second language. In To read and write. http://www.skolverket.se

Strijbos, J.-W., Martens, R. L., Prins, F. J., \& Jochems, W. M. G. (2006). Content analysis: What are they talking about? Computers \& Education, 46, 29-48. doi:10.1016/j.compedu.2005.04.002

Sun, P.-C., Tsai, R. J., Finger, G., Chen, Y.-Y., \& Yeh, D. (2008). What drives a successful e-Learning? An empirical investigation of the critical factors influencing learner satisfaction. Computers \& Education, 50, 1183-1202. doi:10.1016/j.compedu.2006.11.007

Suthers, D. D. (2006). Technology affordances for intersubjective meaning making: A research agenda for CSCL. International Journal of Computer-Supported Collaborative Learning, 1 . doi:10.1007/s11412-006-9660-y

Swann, J. (2010). A dialogic approach to online facilitation. Australian Journal of Educational Technology, 26, 50-62.

Topping, K. (2005). Trends in peer learning. Educational Psychology, 25, 631-645. doi:10.1080/01443410500345172

Topping, K. (1998). Peer assessment between students in colleges and universities. Review of Educational Research, 68, 249-276. doi:10.3102/00346543068003249

Toulmin, S. E. (1958). The uses of argument. Cambridge: Cambridge University Press.

van der Pol, J., van den Berg, B. A. M., Admiraal, W. F., \& Simons, P. R. J. (2008). The nature, reception, and use of online peer feedback in higher education. Computers \& Education, 51, 1804-1817. doi:10.1016/j.compedu.2008.06.001

Wegerif, R. (2006). A dialogic understanding of the relationship between CSCL and teaching thinking skills. International Journal of Computer-Supported Collaborative Learning, 1, 143-157. doi:10.1007/s11412-006-6840-8

Weinberger, A., \& Fischer, F. (2006). A framework to analyze argumentative knowledge construction in computer-supported collaborative learning. Computers \& Education, 46, 71-95. doi:10.1016/j.compedu.2005.04.003

Wiliam, D. (2011). Embedded formative assessment. Bloomington: Solution Tree Press. doi:10.1017/CBO9780511794537

Vonderwell, S. (2003). An examination of asynchronous communication experiences and perspectives of students in an online course: A case study. The Internet and Higher Education, 6, 77-90. doi:10.1016/S1096-7516(02)00164-1 